\title{
Gradhiva
}

GRADHIV

Revue d'anthropologie et d'histoire des arts

$31 \mid 2020$

L'idéal du musicien et l'âpreté du monde

\section{André Leroi-Gourhan, La Civilisation du renne, avant- propos de Michel Guérin}

Paris, Encre marine, 2019 [1936]

\section{Laurent Olivier}

\section{OpenEdition}

\section{Journals}

Édition électronique

URL : http://journals.openedition.org/gradhiva/5197

DOI : 10.4000/gradhiva.5197

ISSN : 1760-849X

\section{Éditeur}

Musée du quai Branly Jacques Chirac

Édition imprimée

Date de publication : 2 septembre 2020

Pagination : 169-170

ISBN : 978-2-35744-131-6

ISSN : 0764-8928

\section{Référence électronique}

Laurent Olivier, «André Leroi-Gourhan, La Civilisation du renne, avant-propos de Michel Guérin », Gradhiva [En ligne], 31 | 2020, mis en ligne le 31 mars 2021, consulté le 03 avril 2021. URL : http:// journals.openedition.org/gradhiva/5197 ; DOI : https://doi.org/10.4000/gradhiva.5197

Ce document a été généré automatiquement le 3 avril 2021.

(c) musée du quai Branly 


\section{André Leroi-Gourhan, La Civilisation du renne, avant-propos de Michel Guérin}

Paris, Encre marine, 2019 [1936]

Laurent Olivier

\section{RÉFÉRENCE}

André Leroi-Gourhan, La Civilisation du renne, avant-propos de Michel Guérin. Paris, Encre marine, 2019 [1936], $224 \mathrm{p}$. 
andré leroi-gourhan

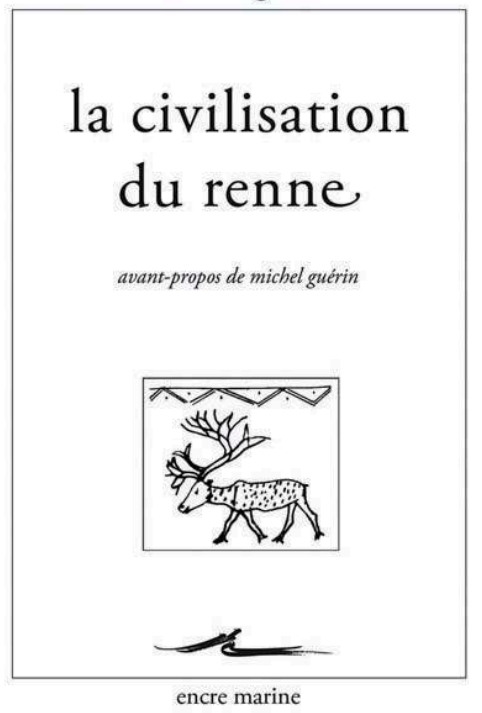

1 C'est un jeune homme aux allures de Tintin qui assiste, à partir de 1930, aux cours de Marcel Mauss sur les « peuples primitifs » à l'École pratique des hautes études (EPHE). Tel un petit reporter explorateur qui parcourt le monde, on reconnaît le jeune LeroiGourhan à ses pantalons de golf, son veston aux poches déformées et sa chevelure épaisse qu'il peigne soigneusement en arrière. Il y ajoute un béret, qu'il porte presque derrière la tête, et une pipe, qu'il serre entre ses dents. S'il semble déjà prêt à embarquer, il n'a guère, pour le moment, voyagé qu'en esprit - dans les textes et surtout au contact des objets, qui ouvrent l'accès à d'autres mondes à qui sait les observer.

2 Au moment où il publie son tout premier livre, La Civilisation du renne, Leroi-Gourhan est avant tout un garçon de musée, fort d'une expérience remarquable pour un étudiant de 25 ans. De 1930 à 1933, il s'est formé aux musées Cernuschi et Guimet, où il a découvert l'art animalier des bronzes chinois - et surtout la manière dont ces images, désormais muettes, ont reproduit et codifié des représentations de mythes de la Chine ancienne ${ }^{1}$. Puis il a été recruté comme collaborateur bénévole au musée d'Ethnographie du Trocadéro, dont Paul Rivet a entrepris la rénovation avec Georges-Henri Rivière. À 23 ans, alors qu'il participe à la gestion des collections et à l'accueil des chercheurs, on lui confie sa première exposition sur les Eskimos. Pendant son service militaire, Rivet lui obtient une mission à Londres, pour y étudier la classification des collections et leur installation muséographique au British Museum et au Victoria Museum. Ainsi, à l'Institut d'ethnologie de Paris, Leroi-Gourhan prendra ensuite en charge les travaux pratiques sur la muséologie et la technologie comparée.

3 Il en tirera un article sur "L'ethnographie et la muséographie », publié en 1936 dans la Revue de synthèse, qui se présente comme un véritable programme. Les productions matérielles des sociétés passées et actuelles sont investies d'un potentiel cognitif considérable, fait-il valoir ; car «l'objet, qui porte un nom, matérialise une technique, 
garde l'empreinte d'un mythe et possède un rôle social et un sens esthétique ». En ce sens, les créations matérielles occupent une place cruciale, « au carrefour de toutes les disciplines "; elles font notamment se rencontrer l'ethnologue (qui les collecte sur le terrain) et le muséographe, qui les conserve au musée ou les présente en exposition².

Cette intense activité professionnelle et scientifique n'est malheureusement pas rémunérée ; aussi, pour être payé, le jeune Leroi-Gourhan tente alors, sans succès, de faire éditer des recueils de contes et légendes destinés à la jeunesse jusqu'à ce que, enfin, en juillet 1935, il obtienne un contrat d'édition grâce à Pierre Deffontaines, dont il suit les cours de géographie préhistorique à l'École d'anthropologie. Chez Gallimard, Deffontaines dirige la collection "Civilisations » et lui offre d'y contribuer. C'est ainsi que naît La Civilisation du renne, volume pour lequel Leroi-Gourhan ne dispose que de trois mois afin de rédiger le manuscrit.

5 Comme beaucoup l'ont noté, il y a déjà tout Leroi-Gourhan dans ce premier livre, qui s'annonce, a-t-on dit, comme "un livre pionnier de son œuvre entière ${ }^{3}$ ». Il y a déjà cette idée, à proprement parler sidérante, selon laquelle le présent (ethnographique) est la clé de compréhension du passé (préhistorique ou archéologique). C'est le renne, en tant que condition de subsistance des communautés humaines dans la toundra-taïga des régions arctiques actuelles comme dans celles de l'Europe pléistocène, qui fait civilisation. Et c'est la cohérence de l'équipement technique de ces sociétés, passées et présentes, qui révèle le dialogue que celles-ci entretiennent avec leur environnement interaction qui constitue, fondamentalement, leur culture, et conditionne leur devenir. En sorte que ce présent ethnographique permet de reconstituer une ethnologie du plus lointain passé préhistorique de l'humanité ${ }^{4}$ : ce n'est pas tant que les outils actuels ressemblent à ceux du passé - et témoigneraient donc d'activités similaires, de préoccupations analogues -, c'est bien plutôt que la distinction passé-présent s'efface d'elle-même devant des actions techniques nécessairement convergentes lorsqu'elles s'appliquent à des milieux identiques ; car «tout geste de l'homme, souligne LeroiGourhan, est une réaction contre le milieu ${ }^{5}$ ».

Ouvrage de jeunesse accueilli par Lucien Febvre comme un « livre de jeune homme », $L a$ Civilisation du renne est dédiée à Marcel Mauss ${ }^{6}$. Celui-ci n'a pourtant qu'une piètre opinion de la géographie de Deffontaines, et de sa collection "Civilisations», dont l'ambition affichée se borne à appréhender « la vie des hommes gravitant autour d'un produit ${ }^{7} »$. Leroi-Gourhan aurait-il rallié ce «camp adverse» avec lequel Mauss identifiait Deffontaines ${ }^{8}$ ? Selon Philippe Soulier, son biographe, ce geste du jeune Leroi-Gourhan est "surprenant", entre "naïveté involontaire", imputable à son « impétuosité » de jeunesse, et " inexpérience des coutumes universitaires ${ }^{9}$ ». Pour les lecteurs de l'œuvre de Mauss, cet essai audacieux, qui amalgame les disciplines sciences naturelles, géographie, ethnologie, archéologie préhistorique... - sans que son auteur ne choisisse vraiment son angle d'étude ni ne l'inscrive dans une démarche intrinsèquement anthropologique, ne pouvait que s'éloigner en effet de l'œuvre de l'héritier de Durkheim ${ }^{10}$.

7 Tentative de " coordination » de disciplines volontiers considérées comme étrangères les unes aux autres, La Civilisation du renne est néanmoins manifestement nourrie des cours de Mauss, dont s'est imprégné Leroi-Gourhan. Ceux de 1932-1933 avaient porté sur « les rapports entre les religions et civilisations des peuples de l'Est et du Nord sibérien », et ceux de 1933-1934 sur les "éléments cosmologiques [...] des mythologies des peuples dits paléo-asiatiques ", dont l'étude s'était poursuivie en 1934-1935 et en 
1935-1936 par un examen des «notions cosmologiques des peuples de l'Asie nordorientale $^{11} »$. Leroi-Gourhan avait d'ailleurs participé au séminaire de 1934-1935, en présentant une conférence sur le chamanisme. Mauss, qui avait étudié les cultures arctiques, était donc directement concerné par le projet de son élève ; mais surtout ce bourreau de travail lui rappelait irrésistiblement quelqu'un d'autre, cher à son cœur.

Mauss, en effet, ne pouvait pas ne pas entrevoir en ce jeune homme enthousiaste, apprenti muséographe et grand dévoreur de livres, le spectre de celui qui avait été l'ami de sa vie, son "jumeau de travail », son authentique frère spirituel en somme : Henri Hubert, mort trois ans seulement avant l'arrivée de Leroi-Gourhan à l'EPHE. Conservateur adjoint au musée des Antiquités nationales de Saint-Germain-en-Laye, Hubert s'était employé à reconstruire une " ethnographie préhistorique de l'Europe ", grâce à la mise en ordre muséographique des productions matérielles laissées par les sociétés du passé. L'alter ego de Mauss voyait dans l'espace muséologique un «microcosme» permettant de représenter en réduction l'histoire du monde, en rendant visibles l'éclosion et la diffusion des styles et des techniques ${ }^{12}$. Pour Hubert et Mauss, ce temps des objets, des rites et des cultures se déployait dans une dimension fondamentalement qualitative et non quantitative, conformément au temps conventionnel de la chronologie. Aussi, lorsque l'on abordait l'étude des productions matérielles de l'humanité - le "côté purement matériel des réactions humaines ", écrira Leroi-Gourhan ${ }^{13}$-, il s'agissait d'entrer dans un régime de temporalité radicalement nouveau et différent : celui de la mémoire culturelle, à l'intérieur duquel le passé n'en finit pas de se recomposer, de se réactualiser en somme, dans sa propre posthistoire.

Dans sa Civilisation $d u$ renne, le jeune Leroi-Gourhan voit lui-aussi l'histoire de l'humanité sous la forme d'un paysage mental, dans lequel les manifestations de la mémoire multimillénaire des productions humaines s'étendent à l'espace du monde habité. D'un puits sans fond, qui s'enfonce dans les profondeurs de la préhistoire ancienne, remontent lentement des «couches » culturelles, qui s'élancent telles des «vagues» à la surface des continents. Les cultures actuelles du renne, que l'on rencontre sur tout le cercle arctique, de la Sibérie au nord de l'Europe, en passant par le nord $\mathrm{du}$ continent nord-américain, ne sont que des extensions de couches plus anciennes, émises par un fonds du paléolithique supérieur - aujourd'hui éteint, mais toujours puissamment actif. Le présent, sous cet angle, n'est que la projection d'un passé imperceptible, car infiniment éloigné de nous, dont la préhistoire révèle la profondeur vertigineuse, et paradoxalement son intemporalité.

10 Comme l'avait relevé Febvre, il y a bien, dans La Civilisation du renne, une "masse de faits et d'idées à méditer », qui ouvrent « des perspectives singulièrement larges [...] sur le plus lointain passé de l'humanité14 ${ }^{14}$. La pensée de Leroi-Gourhan, que l'on voit prendre forme ici, appelle en effet à la méditation. En annihilant l'immensité de la distance chronologique qui sépare l'actuel de la très haute antiquité préhistorique, sa démarche produit un effet de dépaysement intellectuel. Ce faisant, elle interroge la temporalité à l'œuvre dans l'épanouissement et la dissolution des cultures qui jalonnent l'histoire de l'humanité jusqu'à nos jours. Prolongeant la pensée d'Hubert dans une direction inattendue, l'approche ébauchée dans La Civilisation du renne invite à rechercher toujours plus profondément les manifestations de ce mouvement apparemment intarissable, qui transmet le passé à l'avenir et transforme l'ancien en 
nouveau. S'appellerait-on Leroi-Gourhan, la recherche de toute une vie ne saurait, assurément, y suffire.

\section{NOTES}

1. André Leroi-Gourhan, «L'art animalier dans les bronzes chinois », Revue des arts asiatiques 9 (4), $1936: 179-189$.

2. André Leroi-Gourhan, «L'ethnographie et la muséographie », Revue de Synthèse 9 (1), 1936 : 27-30.

3. Michel Guérin, "Avant-propos », in Leroi-Gourhan, La Civilisation du renne, Paris, Encre marine, 2019 [1936] : XXX.

4. ibid. : 46 ; ce sera la démarche développée dans la fouille du site paléolithique de Pincevent (voir André Leroi-Gourhan et Michel Brézillon, Fouilles de Pincevent : essai d'analyse ethnographique d'un habitat magdalénien, Paris, CNRS, 1972).

5. André Leroi-Gourhan, op. cit. : 6.

6. Lucien Febvre, «Zoologie, ethnologie, histoire sociale », Annales d'histoire économique et sociale 9 (44), $1937: 212$.

7. Comme le précise le programme de la collection.

8. André-Georges Haudricourt et Alban Bensa, «Entretien », in Le Portique. Revue de Philosophie et de sciences humaines 27, $2011: 158$.

9. Philippe Soulier, André Leroi-Gourhan (1911-1986) : une vie, Paris, CNRS, $2018: 40$.

10. Marcel Fournier, Marcel Mauss, Paris, Fayard, 1994 : 602-605; Philippe Soulier, op. cit. : 44. Lucien Febvre lui reproche un « rassemblement de faits un peu disparates » et un manque de « rigueur dans la marche logique du raisonnement » (art. cit. : 212).

11. Philippe Soulier, op. cit. : 25.

12. Laurent Olivier, "Penser le temps des vestiges du passé. Henri Hubert et l'archéologie des Antiquités nationales : une tentative d'ethnographie préhistorique ", in Laurent Olivier (dir.), La Mémoire et le Temps: l'œuvre transdisciplinaire d'Henri Hubert (1872-1927), Paris, Demopolis, 2017 : 119-150.

13. André Leroi-Gourhan, op. cit. : 6-7.

14. Lucien Febvre, art. cit.: 212.

\section{AUTEURS}

\section{LAURENT OLIVIER}

laurent.olivier[at]culture.gouv.fr 